\title{
Risk Management: The relationship between perceived risk factors of crowd disaster and perceived safety in large buildings
}

\author{
Mohammed Alkhadim, Kassim Gidado and Noel Painting \\ ${ }^{1}$ University of Brighton, School of Environment \& Technology, BN2 4GJ, UK \\ M.Al-Khadim@brighton.ac.uk ; K.I.Gidado@brighton.ac.uk ; N.J.Painting@brighton.ac.uk
}

\begin{abstract}
Poor risk management within large buildings such as sport stadiums, concert halls, and religious buildings have resulted in crowd disasters in various venues across the world. Within the built environment, safety is considered in two main parts: objective safety (normative and substantive) and subjective safety (perceived). Facilities management within large buildings used by large crowds must involve effective risk management as a key component. (Fruin 1993), suggested that Force, Information, Space and Time (FIST) are the main factors that influence the occurrence of crowd disaster. It has also been theorised that poor perceived safety alone could result into crowd disaster. By using the FIST model, this paper investigates the relationship between the four critical FIST factors and perceived safety in large buildings. The research chose to use the Holy Mosque in Makkah as a case study. The Holy Mosque is a large building of 356,800 square metres with a maximum capacity of two million users (pilgrims). Data was collected using iPad devices via a self-administered questionnaire distributed to 1,940 pilgrims of 62 different nationalities. The results were analysed using SPSS for descriptive analysis and AMOS 22 for Structural Equation Modelling (SEM). The findings clearly confirmed that there is a significant relationship between the FIST factors and perceived safety in large buildings. These findings will inform design consultants and facilities managers as they design and/or manage such facilities.
\end{abstract}

Keywords: facilities management, risk management, perceived safety, crowd safety, crowd disaster, structural equation modeling.

\section{Introduction}

Safety in built environment is classified into objective safety and subjective safety (perceived safety). In an organizational context, objective safety is measured as the actual number of or the risk of incidents or injuries occurring. Subjective safety is intangible and refers to the feeling or perception of being safe or unsafe 
Risk Management: The relationship between the risk factors of crowd disaster and perceived safety in large buildings

within a specified period. Numerous studies have been undertaken on objective safety in the built environment, but there has been a lack of research on subjective safety (perceived safety) particularly in large buildings where large numbers of users attend an event.

(Dickie 1995), confirmed that poor risk management in large buildings or spaces during an event has led to many crowd disasters across the world. (Booty 2009), stated that each large building used by large numbers of people (crowd) normally has diverse types and levels of risk requiring an effective management approach. Experts have defined risk management as a proactive approach to eliminate threats to an organization through anticipating, identifying, assessing and mitigating the possible risks. The British Institute of Facilities Management (BIFM 2014), have classified Risk Management (RM) as one of the 24 key components of Facilities Management (FM). FM covers all aspects of planning, managing space, designing, environmental control, health and safety and support services. It significantly contributes to the delivery of strategic and operational objectives on a day-to-day basis. When events are held in large buildings, research highlighted that facilities managers must be involved before, during and after the event to reduce risk and enhance safety. Experts have established that organizations that own large space assets for public use often make the risk reduction strategy a priority to enable them gain advantage over their competitors.

It is therefore concluded that FM of large buildings and spaces used by large crowds must involve effective risk management as a key component. In current practice, emphasis is placed on addressing objective safety.

(Fruin 1993), studied this issue and established some of the key factors that influence objective crowd safety however there is a lack of understanding of the issue relating to subjective safety. This study has adopted the factors used by Fruin and used them to investigate whether they affect subjective safety in large buildings and spaces. These factors are referred to by the acronym FIST: Force, Information, Space, and Time. The paper argues that there is a strong relationship between FIST and perceived safety in large buildings by studying the extent to which perceived force, perceived poor information, perceived insufficient space, and perceived poor real time management influence perceived safety.

For this research the Holy Mosque in Makkah, Saudi Arabia was chosen having the largest crowd of any event within a large building.

\section{The Holy Mosque as a Large Building}

The Hajj is a religious event that includes a large number of pilgrims with diverse cultures, ages, genders, nationalities and languages. It is one of the five pillars of Islam and an obligation for Muslims who are capable financially and physically to perform Hajj at least once in their lifetime. Annually around two million pilgrims visit Makkah (also called Mecca) to perform the Hajj, for between 4 to 6 days. This 
Risk Management: The relationship between the risk factors of crowd disaster and perceived safety in large buildings

is considered one of the largest gatherings in the world, and the number of people who wish to perform Hajj is increasing yearly. The rituals of the pilgrimage runs between $8^{\text {th }}$ to $13^{\text {th }}$ Dhul Hijjah (Islamic Calendah) and are mainly concentrated in four holy places: the Holy Mosque, the Mina, Muzdalifah and Arafat. The first holy place the pilgrims visit when they arrive is the Holy Mosque to perform Tawaf and Saee. Tawaf is a movement of the pilgrims around the Kaaba, which is situated in the centre of the Holy Mosque. In Tawaf, pilgrims move around the Kaaba seven times in an anticlockwise direction. While in the Saee, pilgrims walk seven rounds between two points in the Holy Mosque called Safa and Marwah. After visiting the other 3 holy places, they return to the Holy Mosque for another Tawaf and Saee. The Holy Mosque is a large building which can accommodate around 1.2 million worshipers at the same time. The current area of the Holy Mosque is about 356,800 square meters and still expanding.

\section{The Conceptual Model}

According to (Fruin 1993), the FIST elements were derived from personal experiences, analyses of major crowd incidents and traffic flow principles. Indeed, the FIST model was developed based on the real conditions and objective safety. The proposed conceptual model replaces tangible items used by Fruin with perceived situations and their effect on perceived safety. The conceptual model includes one dependent variable (perceived safety) and four independents variables (perceived force, perceived poor information, perceived insufficient space, perceived poor real time management). For this study perceived safety is defined as the feeling (or perception) of an unsafe situation at an event over a specified period. These variables will be empirically and statistically measured.

\subsection{Perceived Safety (PS)}

Perceived safety refers to the feeling (or perception) of an unsafe situation existing during an event. If people feel unsafe for some reason, they panic and often attempt to escape from the real or perceived danger by acting abnormally and/or chaotically by pushing and shoving. Studies in urban design have shown that perceived safety can be affected by the characteristics of the environment, the physical condition, and the configuration of spaces. These perceptions can vary with age, sex, culture, and familiarity with the environment, for example: women and older people have a more diverse sense of safety compared with others. Similarly, someone new to an environment may find it safe because they may not be familiar with specific cues within the context. In crowding studies, it has been highlighted that the perceived safety is closely tied to perceived crowding. Perceived crowding is defined as "the psychological counterpart to population density" (Kim et al., 
Risk Management: The relationship between the risk factors of crowd disaster and perceived safety in large buildings

2016). Perceived safety is negatively affected by the perceptions of crowding - and research has shown that when perception of crowding increase, people's sense of safety declines.

\subsection{Perceived Force (PF)}

Perceived force is the feeling or perception of force by an individual within a crowd which may originate by either seeing, hearing or feeling. There are several consequences that may result from the perceived force which have been termed as indictors (items) within this study. Research has established that force within the crowd is usually created from the interior of the crowd and has two main forms: the self-driven force; and the leaning force that comes from the weights of the bodies. It can reach a high level such that it cannot be easily controlled or resisted due to high pressure of the crowd (Still 2016; Fruin 1993). It is argued by researchers, that the force among people is a significant factor that leads to casualties. (Still 2016), stated that most of the deadliest event disasters involved large crowds (those with the largest number of injuries and fatalities) originate from crowd compression and the subsequent loss of footing or inability to move. (Fruin 1993), pointed out that "horizontal forces sufficient to cause compressive asphyxia would be more dynamic as people push off against each other to obtain breathing space". He confirmed that news media have reported that compressive asphyxia is the main reason of deaths not trampling. Experts argued that when people in a crowd are being swept along with movement and compressed, it can lead to serious injuries and fatalities from suffocation. There is evidence to suggest that most of the people who die from suffocation die because of the enormous pressure on their chests (up to $4500 \mathrm{~N}$ $(1000 \mathrm{lbs}$.)). Forces among people in a crowd are generally created when the density is higher than a certain level, and disaster can occur when the crowd density reaches a critical density.

From the above review, it is clearly demonstrated that 'Force' is a critical factor to crowd safety. This study will test the effect of perceived crowd force on perceived safety in the Holy Mosque during the Hajj. Hence, one hypothesis is formulated as follows: H1: Perceived force has a significant influence on perceived safety.

\subsection{Perceived Poor Information (PPI)}

Before attending an event an individual may consider a wide range of information with regards to the venue and the type of crowd. This information could include the nature of the group, experience with similar groups, familiarity with the venue, crowd behaviour, signage and means of communication between those managing the crowd and the crowd. (Fruin 1993), pointed out that the information includes the means of communication, sights and sounds influencing the perceptions of the group, public address, signs, ticketing, actions and training of personal. It is already established that poor communication before or during an 
Risk Management: The relationship between the risk factors of crowd disaster and perceived safety in large buildings

event is characterized as one of the causes of crowd disaster. Obtaining real time information about the situation of the crowd in large assembly spaces including crowd actions, reactions, real or perceived is therefore essential. Experts have underlined that communication and real time information are key factors in preventing crowd disasters. It is a good practice to set up a communications centre and a centralized crowd management system. Information communicated to - or withheld from - the crowd can influence their perceived safety. Experts have established that communicating with the crowd is essential in maintaining order and managing behavior. Based on the above literature review, the following hypothesis is formulated: H2: Perceived poor information has a significant influence on perceived safety.

\subsection{Perceived Insufficient Space (PIS)}

Space in built facilities includes physical facilities, seating areas, corridors, stairs, escalators, standing areas and lifts. Architects and engineers will typically pay attention to local building codes but may have little regard for people's movement and perception. It has been shown that when the venue does not have enough space to accommodate the crowd and the capacity becomes high, say eight people per square meter, human psychology will usually undergo a change. It is also argued by experts that when people attempt to escape from a possible disaster they rush to an exit ignoring alternative exits made available. (Fruin 1993), has indicated that it is hard to describe the psychological and physiological pressure within a highdensity crowd. Additionally, individuals may lose their control; several studies have shown that crowd density can influence the perceived safety and behaviour (Alnabulsi and Drury, 2014). The bodies within a crowded space are surrounded by heat and thermal insulation to the extent that some people may be weakened and faint. Ineffective or poor use of space is one of the key risk factors in crowd disaster (Still 2016). Critical crowd density is around 1.5 square feet (i.e. 7 persons per square metre). This also relates to the crowd control failure which creates psychological and physical scenarios that causes human stampede. Therefore the following hypothesis: H3: Perceived insufficient space has a significant influence on perceived safety.

\subsection{Perceived Poor Real Time Management (PPRTM)}

(Fruin 1993), argued that real time information and intervention are a key factor for preventing crowd disasters. Time plays an important role in an event, for instance the density of the crowds before the event is much less compared to the rapid egress and heavy crowd densities leaving an event. Research has shown that failure to detect crowd behavior at the right time can lead to injuries and fatalities. Crowd management literature has made it clear that it is a requirement to ensure the flow of the pedestrians does not exceed the capacity of the spaces through which 
Risk Management: The relationship between the risk factors of crowd disaster and perceived safety in large buildings

they are flowing or the capacities of the space in which they are congregating. There is evidence to suggest that lack of consideration is sometimes given to how crowd flow and density can be successfully managed by controlling timings. Hence, the hypothesis is formulated based on the literature review as follows: H4: Perceived poor real time management has a significant influence on perceived safety.

\section{Method}

Primary data used for this study was obtained using group-administered questionnaire. This method is chosen instead of the self-administered approach because of the following: the respondents (pilgrims from all over world) have limited time at Makkah; the need to achieve a high rate of return; and to enable the respondents to seek clarification if any misunderstanding arises (Zohrabi 2013).

The questionnaire encompassed six sections: section one is background information; sections two to five are designed to measure the user (pilgrim) perception with reference to the independent variables (perceived force, perceived poor information, perceived insufficient space, perceived poor real time management), section six refers to the dependent variable (perceived safety).

The items included in the questionnaire were adapted from (Alnabulsi and Drury 2014; Fruin 1993). Several items have been modified to achieve the aim of the study. All the items were measured on a 5-point Likert scale ( $1=$ strongly disagree; $5=$ strongly agree $)$ and some items $(1=$ never occur; $5=$ almost always occurs $)$.

A pilot study was carried out in Makkah in 2016 before the Hajj began in order to evaluate the validity and reliability of the questions and instructions. It aimed to check the clarity of instructions and the items of the questionnaire, to determine the time needed to complete the questionnaire, to ensure the statements were clear and easy (not difficult or complex) to understand and to gain any other useful comments.

The population sampling for this study targeted all the pilgrims (local and coming from outside of the country specifically for the Hajj) during Hajj within the zone of Makkah. A total population size of 1,942,946 pilgrims was determined based on the report provided by Ministry of Hajj and General Authority for Statistics. 1,940 participants were surveyed with an estimated confidence level of 95\% and a 2\% margin of error during the Hajj 2016 (1437 Arabic Calendar). The questionnaire statements were programmed into iPad devices and linked to the database centre at the Hajj and Umrah Research Institute. Twelve experienced and trained postgraduate research students collected the data at different locations in Makkah. The majority were collected at the pilgrims' camps or accommodation.

Structural Equation Modelling (SEM) was used as statistical test for this study. SEM was chosen as a statistical technique for several reasons: Firstly, this study attempts to establish the interrelationship between the FIST factors and perceived safety; latent variables are encountered that cannot be measured directly. Secondly, SEM is a powerful tool that is able to test the model fit to the data and at the same 
Risk Management: The relationship between the risk factors of crowd disaster and perceived safety in large buildings

take into account any measurement error (unreliability) for each latent variable of the constructs being estimated.

Table 1. Factor loading for items and reliability test

\begin{tabular}{|c|c|c|c|c|c|}
\hline Constructs & Items & $\begin{array}{l}\text { Factor } \\
\text { Loading }\end{array}$ & $\begin{array}{l}\mathrm{CR} \\
>0.6\end{array}$ & $\begin{array}{l}\text { AVE } \\
>0.5\end{array}$ & $\begin{array}{l}\text { Cronbach } \\
>0.7\end{array}$ \\
\hline $\mathrm{PF}$ & & & & & \\
\hline & Breathing Difficulties & 0.77 & & & \\
\hline & Crowd Pushing & 0.82 & & & \\
\hline & Movement Difficulties & 0.79 & & & \\
\hline PPI & Crowd Pressure & 0.82 & 0.920 & 0.698 & 0.922 \\
\hline & Health and Safety Information & 0.80 & & & \\
\hline & Communieation & 0.81 & & & \\
\hline & Availability of all types of Signs & 0.88 & & & \\
\hline & Signs Visibility & 0.86 & & & \\
\hline & Warning Signs & 0.83 & & & \\
\hline PIS & & & 0.814 & 0.598 & 0.824 \\
\hline & Activities Areas Densities & 0.71 & & & \\
\hline & $\begin{array}{l}\text { Availability and Distribution of Stairs, } \\
\text { Esealators and Lifts }\end{array}$ & 0.91 & & & \\
\hline & Entrances and Exits Densities & 0.67 & & & \\
\hline PPRTM & & & 0.870 & 0.691 & 0.866 \\
\hline & $\begin{array}{l}\text { Crowd Flows Control } \\
\text { Real Time Information and Intervention }\end{array}$ & 0.81 & & & \\
\hline & $\begin{array}{l}\text { Resi Time Information and Intervention } \\
\text { Waiting Time }\end{array}$ & 0.83 & & & \\
\hline PS & & & 0.808 & 0.514 & 0.804 \\
\hline & $\begin{array}{l}\text { Perceived Risk of Fatalities } \\
\text { Perceeved Risk of Damaged facilities }\end{array}$ & 0.68 & & & \\
\hline & Perceived Risk of Falls, Slips and Trips & 0.76 & & & \\
\hline & Perceived Risk of Trampling or Stampede & 0.71 & & & \\
\hline
\end{tabular}

\section{$5 \quad$ Results}

The data was analysed using the Analysis of Moment Structure (AMOS) for Structural Equation Modeling (SEM). Prior to undertaking the SEM analysis, checks were made to ensure that the collected data is clean and normally distributed. The Confirmatory Factor Analysis (CFA) was also was performed for all latent constructs prior to modelling the interrelationship in SEM. All the measurement items for the latent constructs should have an acceptable factor loading of 0.60 and above in an effort to improve the fitness level of the measurement model (Awang 2015). Initially, the total number of all items was 29 before conducting the CFA procedures. With the purpose of achieving the minimum fitness index, 10 items were deleted one at a time and some were linked. After conducting the CFA procedures the model contains 19 items with an acceptable factor loading of at least 0.60 as detailed in Table1.

Research has shown that to establish convergent validity, the model fit must be adequate, and the average variance extracted (AVE) must exceed 0.50 . The results of AVE for all constructs as presented in Table1 have achieved the standard minimum required level of 0.50 .

Two reliability tests have been undertaken for this study: composite reliability (CR) and Cronbach's alpha. This paper has used both tests to guarantee the reliability of the data before conducting any further analysis. Other researchers have claimed that $\mathrm{CR}$ is more accurate than Cronbach's alpha because it does not assume that the loadings or error terms of the items are equal. Both tests CR and Cronbach's Alpha have met the standard minimum threshold of 0.60 and 0.70 respectively. This 
Risk Management: The relationship between the risk factors of crowd disaster and perceived safety in large buildings

indicates the acceptability of internal consistency and confirms that all the items used in the model are technically free from the errors.

Overall, the result of the assessment of the measurement model shows solid evidence of validity and reliability. It clearly shows that the items on each construct of the study are considered reliable.

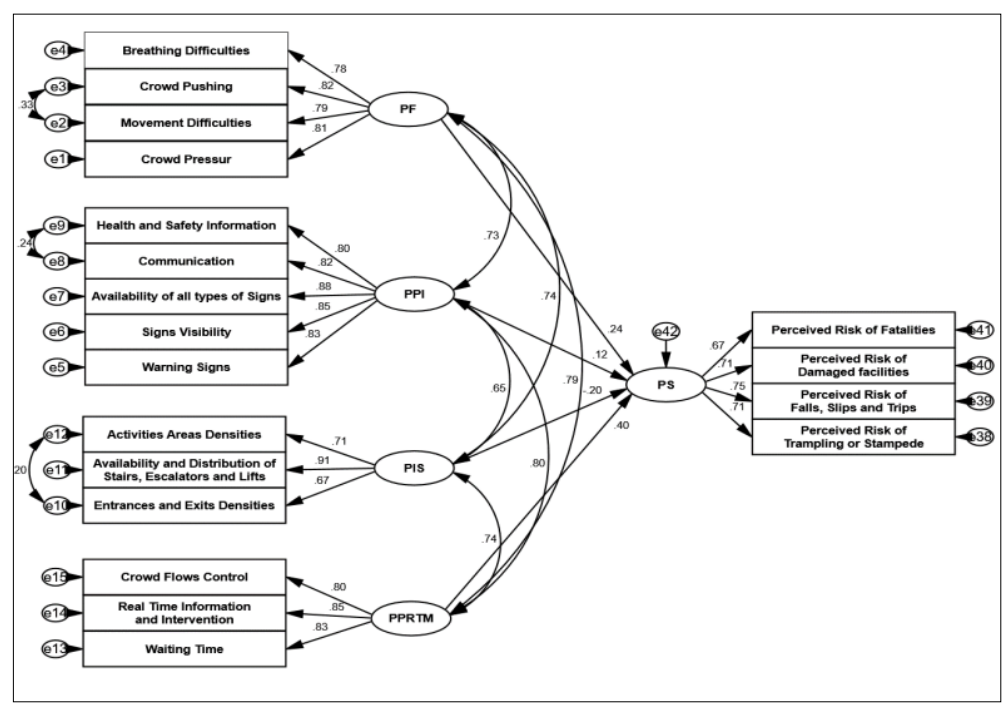

Fig. 1 Regression Path Coefficient for the Structural Model

The structural model as shown in Figure 1 presents the interrelationship among the variables. It consists of 4 unobserved exogenous constructs (perceived force, perceived poor information, perceived insufficient space, and perceived poor real time management) and one unobserved endogenous constructs (perceived safety). Based on the fit indexes, the model is a good fit and all measures of comparative fit index $(\mathrm{CFI})=0.979$, standardized root mean square residual $(\mathrm{SRMR})=0.032$, and root mean square error of approximation (RMSEA) $=0.043$ have achieved the required level. (Hu and Bentle 1999; Awang 2015), recommend a CFI $\geq 0.90$, SRMR $\leq 0.08$, and RMSEA $\leq 0.06$ for acceptable model fit. Consequently, the model is accepted for further analysis and testing the hypothesis.

Table 2 shows the path for the construct and its coefficient as well as the significance for that particular path. It presents the effect of each exogenous construct on the respective endogenous construct. The results reveal that all the independent variables have significant effect on perceived safety. The path coefficient of perceived force to perceived safety is 0.189 . This value indicates that for every one-unit increase in the perceived force, its effect on perceived safety would increase by 0.189 units. And more importantly there is a significant effect $(\mathrm{P}<0.001)$ of all constructs on perceived safety. The impact of perceived poor information on perceived safety is 0.088 . In contrast, perceived insufficient space 
Risk Management: The relationship between the risk factors of crowd disaster and perceived safety in large buildings

has a negative impact on perceived safety by -0.193 . The perceived safety is also affected by perceived poor real time management by 0.305 .

Table 2. Regression Weight for path coefficient and it's Significant.

\begin{tabular}{llll}
\hline Path Construct relationship & Estimate & P-value & Hypothesis \\
\hline H1: Perceived force $->$ Perceived safety & .189 & $* * *$ & Supported \\
\hline H2: Perceived poor information.> Perceived safety & .088 & $.010^{* *}$ & Supported \\
\hline H3: Perceived insufficient Space $->$ Perceived safety & -.193 & $* * *$ & Supported \\
H4: Perceived poor real time management -> & .305 & $* * *$ & Supported \\
Perceived safety & & &
\end{tabular}

Note: $=* \mathrm{p}<0.05, * * \mathrm{p}<0.01, * * * \mathrm{p}<0.001$

\section{Discussion}

The findings clearly supported our hypotheses and the proposed conceptual model. It has been confirmed that the perception of the users (pilgrims) about safety in large buildings (Holy Mosque) during religious event (Hajj) are strongly affected by four main factors: perceived force, perceived poor information, perceived insufficient space and perceived poor real time management.

The analyses have revealed that the perceived force has a positive impact on perceived safety by 0.189 . Increase in level of feeling (or perception) of breathing difficulties, crowd pushing, difficulty in movement, and crowd pressure make the pilgrims feel unsafe.

Perceived poor information also has a positive effect on perceived safety by 0.088 , which means that the perception of pilgrims about safety can be effected by poor information. The results could be interpreted to mean that pilgrims felt unsafe due to a number of reasons including: insufficient health and safety information provided to them, poor communication between the pilgrims and police/security at the Holy Mosque, inadequate signs, unclear signs, and insufficient warning signs. Thirdly, perceived poor real time management has a positive effect on perceived safety by 0.305 . This is because of three main reasons: loss of crowd control, poor real time information and intervention, and waiting time to use the facilities was unacceptable.

In contrast, there is a negative relationship between perceived insufficient space and perceived safety by -0.193 . This is an interesting finding; it means that the more the pilgrims perceive space to be insufficient the less they feel unsafe. This confirms the findings of (Alnabulsi Drury 2014), which found that increasing level of crowd density reduces the pilgrim's feeling of being unsafe. They argued this to be the case because the pilgrims were high in social identification as Muslims. They are of the view that social identification should moderate the negative effect of crowd density on reported safety at the Holy Mosque. The finding in this paper may 
Risk Management: The relationship between the risk factors of crowd disaster and perceived safety in large buildings

suggest that the negative effect of perceived insufficient space on perceived safety may only be applicable to conventional dense crowds made up of individuals in unity of purpose with a common social identity - social category membership with high expectations of social support from others in the crowd.

\section{Conclusion}

This study used Structural Equation Modeling technique to examine the relationships between perceived force, perceived poor information, perceived insufficient space, perceived poor real time and perceived safety factors in a large building (Holy Mosque) during the Hajj event. It was found that all perceived FIST factors have significant effect on perceived safety.

After conducting the CFA procedures, 19 items with an acceptable factor loading of at least 0.60 were identified (as detailed in Table1). In order to reduce the risk or potentiality of a crowd disaster at the Holy mosque, those items under Perceived Force (PF), Perceived Poor Information (PPI), Perceived Insufficient Space (PIS) and Perceived Poor Real Time Management (PPRTM) need to be considered by facilities managers. The result of the assessment of the measurement model has shown solid evidence of validity and reliability. It also clearly confirms that the items on each construct of the study are reliable.

\section{References}

Alnabulsi H, Drury J (2014) Social identification moderates the effect of crowd density on safety at the Hajj. Proceedings of the National Academy of Sciences of the United States of America 111: 9091-9096. doi:10.1073/pnas.1404953111

BIFM (2014) The Facilities Management Professional Standards

Dickie JF (1995) Major crowd catastrophes. Safety Science 18: 309-320

Fruin JJ (1993) The causes and prevention of crowd disasters. Engineering for crowd safety: $1-10$

Kim D, Lee K, Sirgy J (2016) Examining the differential impact of human crowding versus spatial crowding on visitor satisfaction at a festival. Journal of Travel \& Tourism Marketing 33: 293-312. doi/full/10.1080/10548408.2015.1024914.

Mehta V (2013) The Street: A Quintessential Social Public Space. Routledge

Still GK (2016) Crowd safety and Risk analysis. http://www.gkstill.com/ExpertWitness/CrowdDisasters.html.

Zohrabi M (2013) Mixed Method Research: Instruments, Validity, Reliability and Reporting Findings. Theory and Practice in Language Studies 3: 254-262 